\title{
An experimental approach to ground stone tool manufacture
}

\author{
Andrea Squitieri ${ }^{1}$, David Eitam ${ }^{2}$ \\ 1. Ludwig-Maximilians-Universität München, Germany. Email: andrea.squitieri@gmail.com \\ 2. Independent researcher, Hararit, Israel. Email: david.eitam@mail.huji.ac.il
}

\begin{abstract}
:
The manufacture of ground stone tools has long been a topic of interest for archaeologists. Ground stone tools made of specific stone types (e.g., limestone, basalt, granite) have been investigated with regards to the technology chosen by craftsmen, the manufacturing process, working tools and tool mark analysis. Here, we present the results of an experimental study of the manufacture of a basalt mortar. In particular, the strategy we adopted in designing this study was to present a method for producing a basalt mortar by pecking and abrading with basalt tools. The study was designed and conducted by A. Squitieri and D. Eitam, while the mortar was made by the sculptor D. Yassur. The goals of our experiment were to observe and document the choices made by the sculptor in creating the mortar, starting from the selection of a basalt cobblestone as the raw material, the tools (made from basalt) he used and the ways he used them. We detected practical problems the sculptor had to overcome during the process, the amount of debitage, and the nature of tool marks in the mortar cavity after the manufacturing process. We documented the entirety of the experiment through photographs and videos. Our experimental production using the expertise of a professional sculpture and his thorough knowledge of basalt offers a better understanding of basalt artefact manufacture, the physical properties of the raw material and the interaction between basalt tools and basalt raw material.
\end{abstract}

Keywords: ground stone tools; technology of production; experimental archaeology; mortar

\section{Introduction}

The category of ground stone tools encompasses a wide range of artefacts (e.g., pestles, querns, handstones) whose manufacturing techniques include not only the creation of the form through grinding (as the term "ground stone" indicates) but also a number of other techniques, such as flaking, pecking, and drilling (Wright 1992: 53).

Previous investigations into ground stone tool manufacturing techniques have been carried out mainly through experiments (e.g., Treganza \& Valdivia 1955; Cerutti 1986; Huckell 1986: 36-40; Levanthal \& Seltz 1989; Schneider 1993: 310-42; 1996; Buonasera 2015) and ethnographic observations (e.g., Aschmann 1949; Cook 1973; Hayden 1987: 8-48). In this paper, we will use an experimental approach in the study of ground stone tool

Published by the School of History, Classics and Archaeology, University of Edinburgh ISSN: 2055-0472. URL: http://journals.ed.ac.uk/lithicstudies/

This work is licensed under a Creative Commons Attribution 2.5 UK: Scotland License. 
production techniques to better understand this technology, as this approach is helpful in identifying some of the problems ancient craftsmen had to overcome during manufacture, and provides a benchmark from which to interpret the archaeological materials from a technological point of view (for general discussion on experimental archaeology, see e.g., Malina 1983; Forrest 2008).

In particular, the strategy we adopted in designing this study was to present a method for producing a basalt mortar by pecking and abrading with basalt tools. We do not claim that this specific method used by sculpture D. Yassur is the same method that ancient craftsman used during a particular period since the exact circumstances in which ancient craftsmen worked, as well as the techniques they used, are in most cases unknown. However, we think that the basic manner of production was very similar. Our experimental production using the expertise of a professional sculpture and his thorough knowledge of basalt offers a better understanding of basalt artefact manufacture, the physical properties of the raw material and the interaction between basalt tools and basalt raw material.

D. Yassur's method of making a basalt mortar by coarse and fine pecking, and abrading, is one possible way of mortar manufacture, a method which has been documented archaeologically, for example at the Neolithic site of Sha'ar Hagolan, in northern Israel (Rosenberg \& Garfinkel 2015). Another method of producing mortars, which has been archaeologically documented and experimentally replicated by Bryan (1961), and Schneider \& Osborne (1996), involves isolating a part of the natural cobble by hollowing out a groove around it and then detaching this part by means of percussive blows. Another technique for removal of a portion of the cobble is percussion flaking, which also was documented in ethnographic studies, typically during the initial stage of ground stone tool manufacture prior to reducing the cobble to shape by pecking (e.g., Hayden 1987: 31-35).

Before going into the details of the experiment, we must stress that understanding how ground stone tools were made can be useful to gain insight on some aspects of ancient societies. One theoretical framework which can be used is the "chaîne opératoire", typically applied to pottery production (Lemonnier 1992: 25-50; Roux 2010: 4). The chaîne opératoire framework not only aims to reconstruct the stages of production through which the craftsman transforms a block of raw material into a finished object, but it also aims to identify those variations (both intra- and inter-cultural) in the manufacturing process, which could be linked to the raw material's properties, cultural factors (for example, the craftsman's training, knowledge transmission, the craftsman's role in the society), and traditions defining particular social groups (e.g., gender, ethnicity, social class) or regions. This can also help identify technological innovations and their spread. The study of the chaîne opératoire and the comparison of chaîne opératoires from different periods and cultural milieu can, therefore, provide a bridge between ancient technology and social organisation and at the same time can help identify those cross-cultural aspects of the ancient technology that could be linked to the raw material's properties. It is this last aspect that forms the basis of the experimental approach in this paper.

\section{Research questions and description of the experiment}

Our experiment took place in December 2013 in Israel, where we had the opportunity to observe D. Yassur, a sculptor specialised in working with basalt, produce a small basalt mortar. The experiment was designed to replicate a basalt mortar with a shape corresponding to Wright's pebble-mortar (Wright 1992: 66, no. 15), Adams' rock-mortar (Adams 2001: 128), or Eitam's cupmark (Eitam 2009). Drawings of this type of mortar were shown to the sculptor before the experiment. This type of mortar has a worked, bowl-shaped cavity in an unworked cobblestone. This is a common shape in the ground stone tool repertoire of many 
ancient societies, in both the Old and New Worlds, as this type of tool was commonly involved in food and other material processing (like minerals; e.g., Schneider 1993: 5; Ebeling \& Rowan 2004) and as a container for various materials (e.g., Eitam et al. 2015: fig. 2: E-F). As for the raw material, vesicular (porous) basalt was used for this experiment, as this raw material was often used in the past to manufacture ground stone tools (wherever it was available). The hardness (Mohs scale 7) and resistance to stress of vesicular basalt make it highly durable in various activities involving grinding, pounding or rubbing (Speth 1972: table 1; Wright 1992: 54). The working tools used in our experiment to manufacture the mortar were two tools in non-porous basalt, both with an oblong shape, which will be described below.

The questions we wanted to answer through this experiment were:

- What are the techniques chosen by the sculptor to make the mortar?

- How long does the entire process take?

- What are the effects on both the mortar and the working tools that take place during the manufacturing process?

- What tools are used during the different stages of manufacture?

The entire process was documented with photographs and videos; the sculptor's comments were also recorded to help interpretation. The production stages are described below:

\section{Choice of suitable cobble}

A porous basalt cobble was collected from surface by the sculptor, which had a maximum diameter of about $35 \mathrm{~cm}$ (Figure 1). It had an irregular rounded shape, with one flattish surface (indicating possible water erosion) that could offer a surface suitable for the cavity. The working surface had not been prepared by flaking.

\section{Choice of working tools}

The sculptor chose to work with two oblong tools collected from surface, made of nonporous basalt. Both had a length of about $20 \mathrm{~cm}$, one had a wide blunt point (Figure 1), whereas the other had a wide sharper point, very similar to a chisel point.

\section{Rough and fine pecking}

The sculptor placed the cobble on the ground to better absorb the force of the blow, and began work with the blunt-point tool on the natural flattish surface by pecking. Pecking was done by holding the tool in a slightly oblique position (Figure 2). During the pecking, we noticed a lot of grit and chips being generated. Notably, the tool itself was producing such grit and chips in a discreet quantity. During this phase, the sculptor frequently rotated the object to better reach all the areas of the working surface.

The working-tool tip became sharper and sharper during this phase, which made it more effective and allowed more chips to be detached from the object. It was interesting to note that the oblique pecking was not constant throughout this phase. The sculptor was, from time to time, moving the tool to an upright position, to perform what we refer to as 'fine pecking'. Fine pecking allowed the sculptor to eliminate the sharp edges produced on the working surface by the oblique pecking, making the surface as flat as possible. 


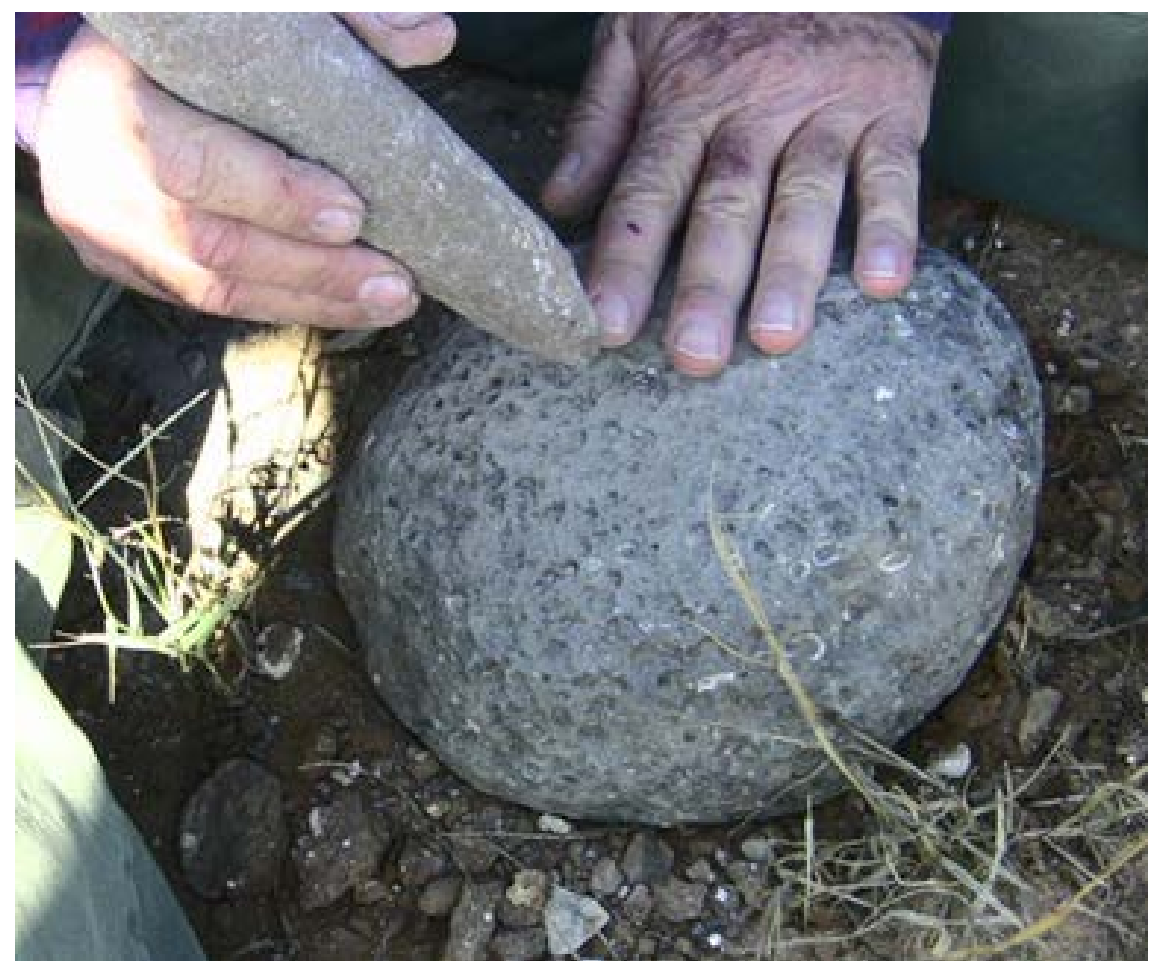

Figure 1. The rounded cobblestone before the cavity was made. The sculptor has the first type of working tool (with a blunt wide point) in his hand.

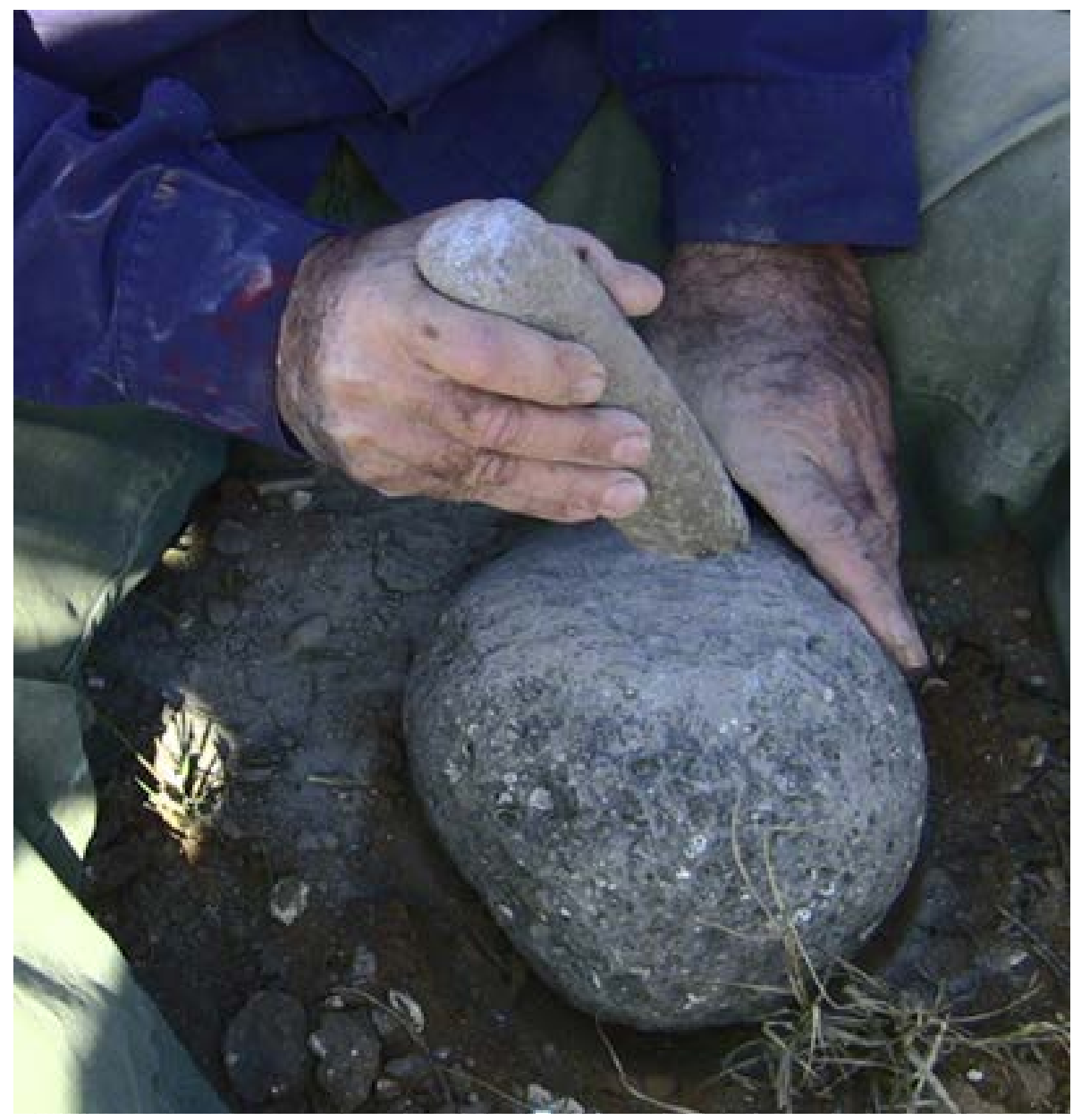

Figure 2. Pecking the surface of the cobblestone using a non-porous basalt tool. 


\section{Defining the edge of the cavity}

Once the surface was flat enough, the sculptor concentrated on the area where he intended to make the shallow cavity; he used the same tool as the previous steps. By holding the tool in a slightly oblique position, David started to work on the interior of the edge of the intended cavity. The blows became more intense and concentrated, and the object was frequently rotated. A shallow depression then became visible (Figure 3). At this point, the sculptor had to rest for about 15 minutes.

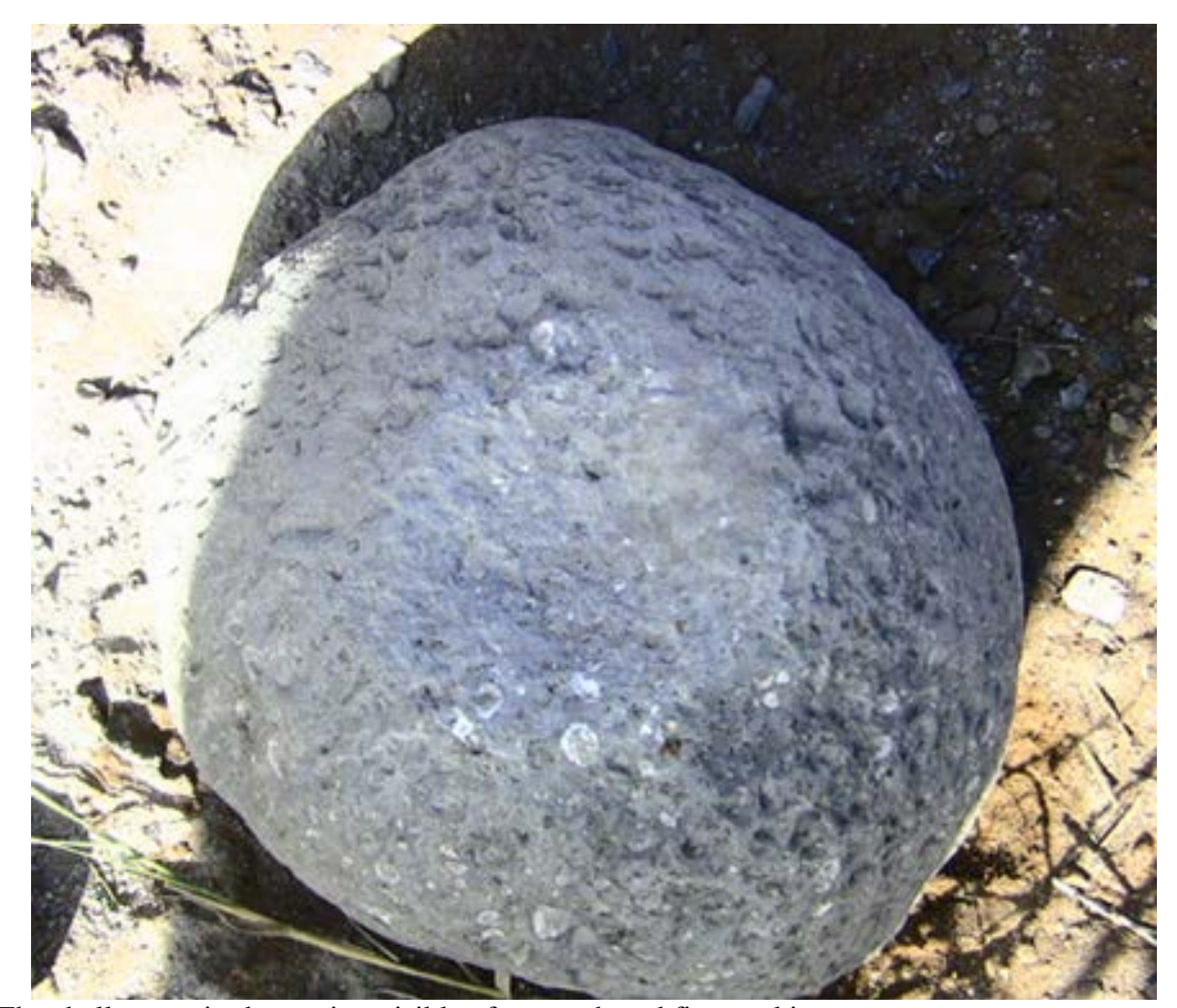

Figure 3. The shallow cavity becoming visible after rough and fine pecking.

\section{Deepening the cavity}

With the shallow depression visible, the sculptor switched tools, using the second tool with the sharp, chisel-shaped tip (Figure 4). He then started to peck holding the tool obliquely inside the shallow cavity. This tool was very effective. Greater amounts of powder and small chips were detached this time, and also the noise generated by the contact of the tool and the object changed to a metallic sound. As before, the working tool itself became greatly chipped during the use. So much powder was produced during this phase that the object being worked was, from time to time, turned over to clear the powder from the working surface.

Once the cavity was made, the sculptor switched back to the first working tool. This time, he used the other end, which had not been used before, and started to finely peck inside the cavity; David held the tool vertically. In this way, he eliminated the sharp edges left behind from the blows of the second, sharper tool. He also better defined the rim by pecking on its surface. At this point, he also used the same tool to smooth the rim and the interior cavity walls. After this process, the sculptor used a water and basalt powder mixture (using the powder discarded earlier, see Figure 5), using the tool on its lateral side to rub one side of the cavity, thus making it highly polished. Water, the sculptor said, helped to mix the powder as well as to decrease friction, giving a better final result. 


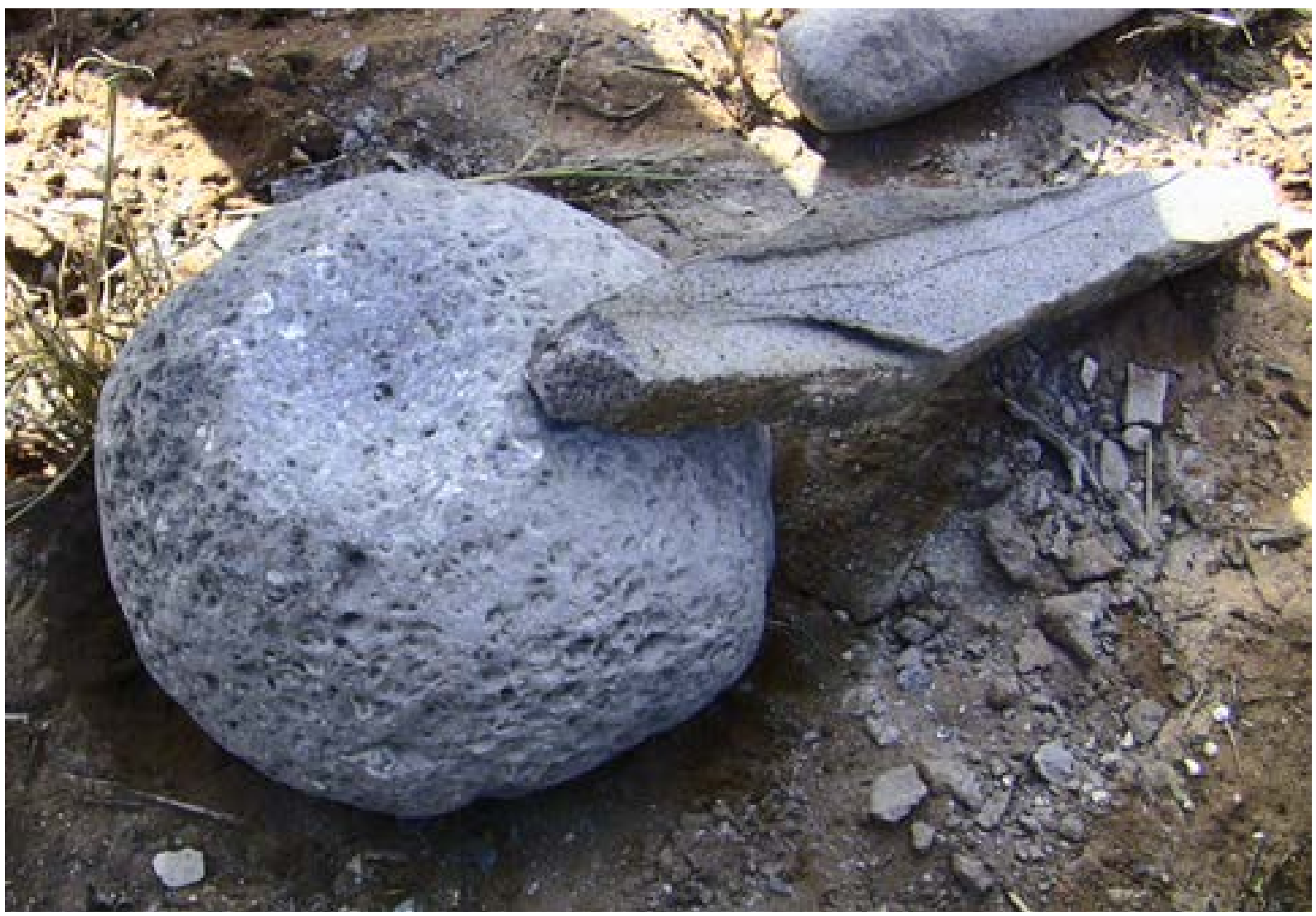

Figure 4. The second working tool with its wide sharp tip.

\section{Ending}

At the end of the process, the cobble was cut using a power saw to separate the cavity (Figure 6). We cut the cobble, leaving the cavity untouched; in order to enable further analysis under binocular microscope and SEM. Such microscopic observations of the tool marks left on the experimental mortar can potentially provide useful insights if compared with similar analyses conducted on unfinished ground stone tools available in the archaeological record.

The manufacturing process took roughly 2 hours with a 15 minute break during which the sculptor rested his arm. Table 1 summarises the quantitative data of this experiment.

\section{Results and conclusions}

The first step of the mortar manufacture, the collection of a suitable cobblestone from the ground, may have also been an option for ancient craftsmen as water-worn cobblestones are ready to use, save the time necessary to quarry a block, and may already display a suitable working surface made flattish by water action. The craftsman simply had to choose a cobblestone that was close enough to the final product shape and size in order to save time and energy. If no such cobblestones were available, they could quarry the necessary raw material. Some ethnographic evidence also shows that the practice of surface collection occurs in more recent times (Hayden 1987: 21-2).

The blunt- and sharp-pointed working tools made of non-porous basalt that the sculptor employed during the experiment proved to be effective for working the basalt and creating the cavity; similar tools must have been adopted by craftsmen who only had access to stone tools. 


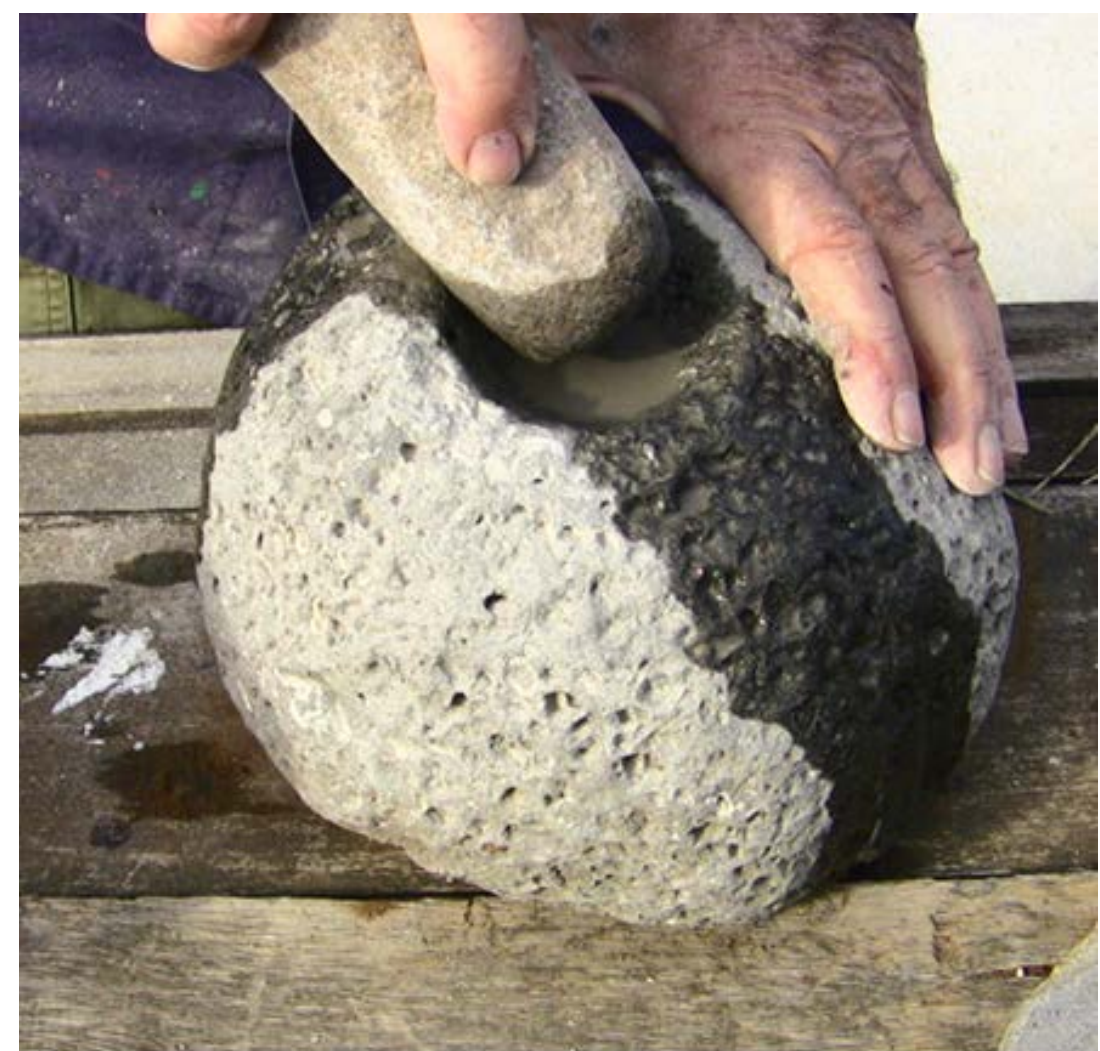

Figure 5. One side of the cavity is being polished by using the tool on its side, mixing water and basalt powder.

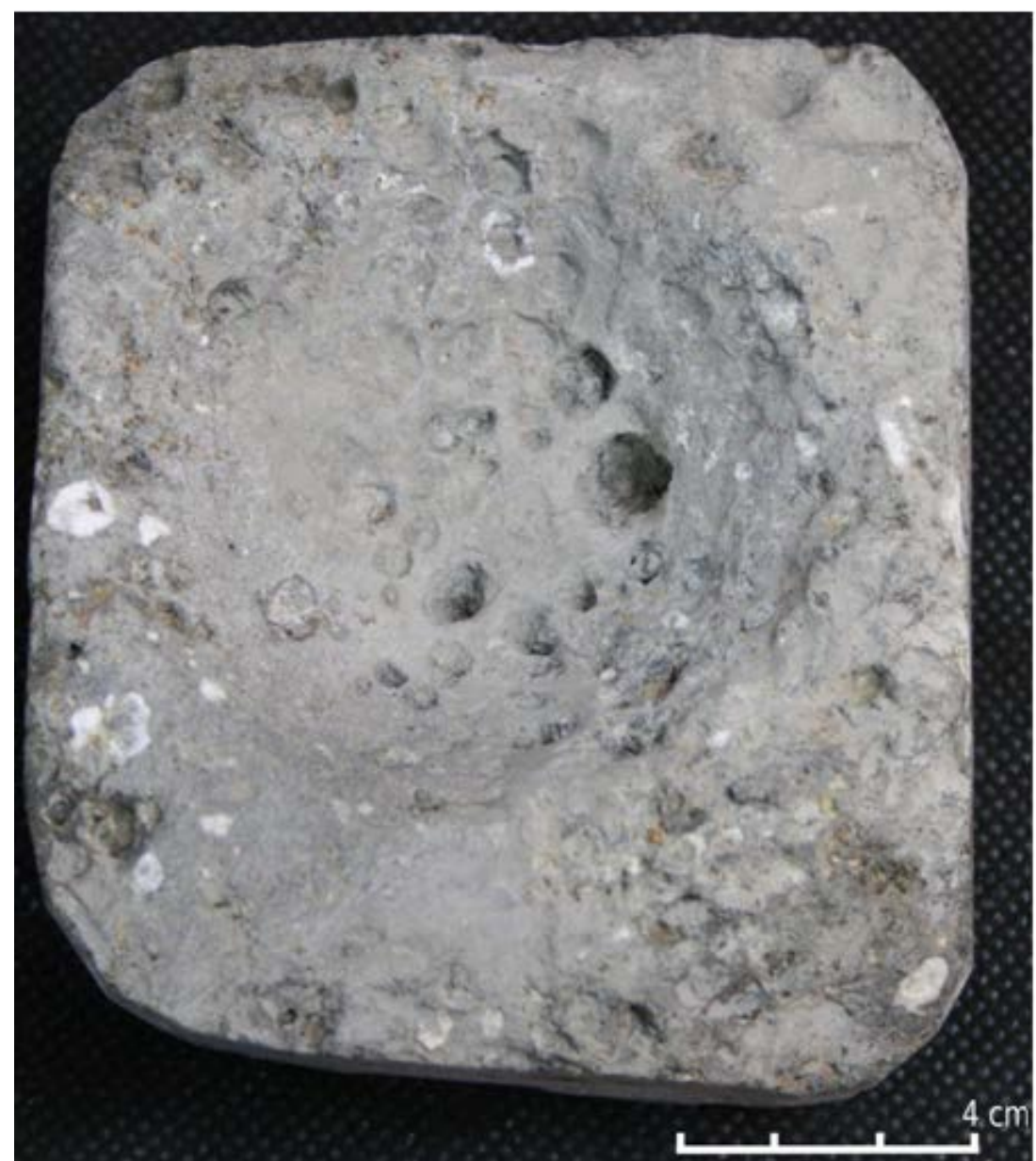

Figure 6. The mortar's cavity after being cut from the cobble at the end of the process. 
Table 1. Results of our experiment for the replication of a basalt mortar.

\begin{tabular}{|c|c|c|c|c|c|}
\hline $\begin{array}{l}\text { Cavity } \\
\text { diameter } \\
(\mathrm{cm}) \\
\end{array}$ & $\begin{array}{c}\text { Cavity } \\
\text { maximum } \\
\text { depth }(\mathrm{cm}) \\
\end{array}$ & $\begin{array}{c}\text { Cavity } \\
\text { capacity }\left(\mathrm{cm}^{3}\right)\end{array}$ & Total time (h) & $\begin{array}{l}\text { Blows } \\
\text { per } \\
\text { hour }\end{array}$ & $\begin{array}{c}\text { Volume } \\
\text { removed per } \\
\text { hour }\left(\mathrm{cm}^{3}\right)\end{array}$ \\
\hline 7.5 & 3.0 & $\begin{array}{c}\text { Ca. } 30 \\
\text { (measured } \\
\text { with sand) } \\
\end{array}$ & $\begin{array}{c}1.75 \text { (excluding } \\
\text { the } 15 \text { minute } \\
\text { break) }\end{array}$ & 7,800 & 17.1 \\
\hline
\end{tabular}

An important observation is that both the working tools and the mortar itself lost much grit and powder and many small chips were made during the process. This suggests the possibility that in the past there was a high rate of working tool discard because of breakage or because the working tools had become less effective after losing the appropriate working edges. A similar phenomenon was observed in both Schneider's (1993: 329) and Levanthal \& Seltz's (1989) experiments. The fact that so much debris resulted from the manufacturing process also leads to the hypothesis that the preferred place for manufacturing such objects was in open air areas, which wouldn't have required cleaning. Moreover, the place of manufacture may also have been near the spot where the raw material was collected.

Interestingly, macroscopic observation of the mortar's cavity at the end of the process revealed that the tool marks left were not as obvious as we expected. Figure 7 shows the interior of the cavity where it was not polished. Tool marks are not very visible: the cavity surface looks corrugated but no clear marks can be discerned. Because this is a modern, unused experimental object, we can rule out the possibility that tools marks were smoothed through use, as can happen with older materials that were used over long periods of time. Hence, to explain the low visibility of tool marks, it can be suggested that the wide blunt point of the working tool and the combination of both rough and fine pecking may have had the effect of eliminating any marks, levelling the surface as it was being worked.

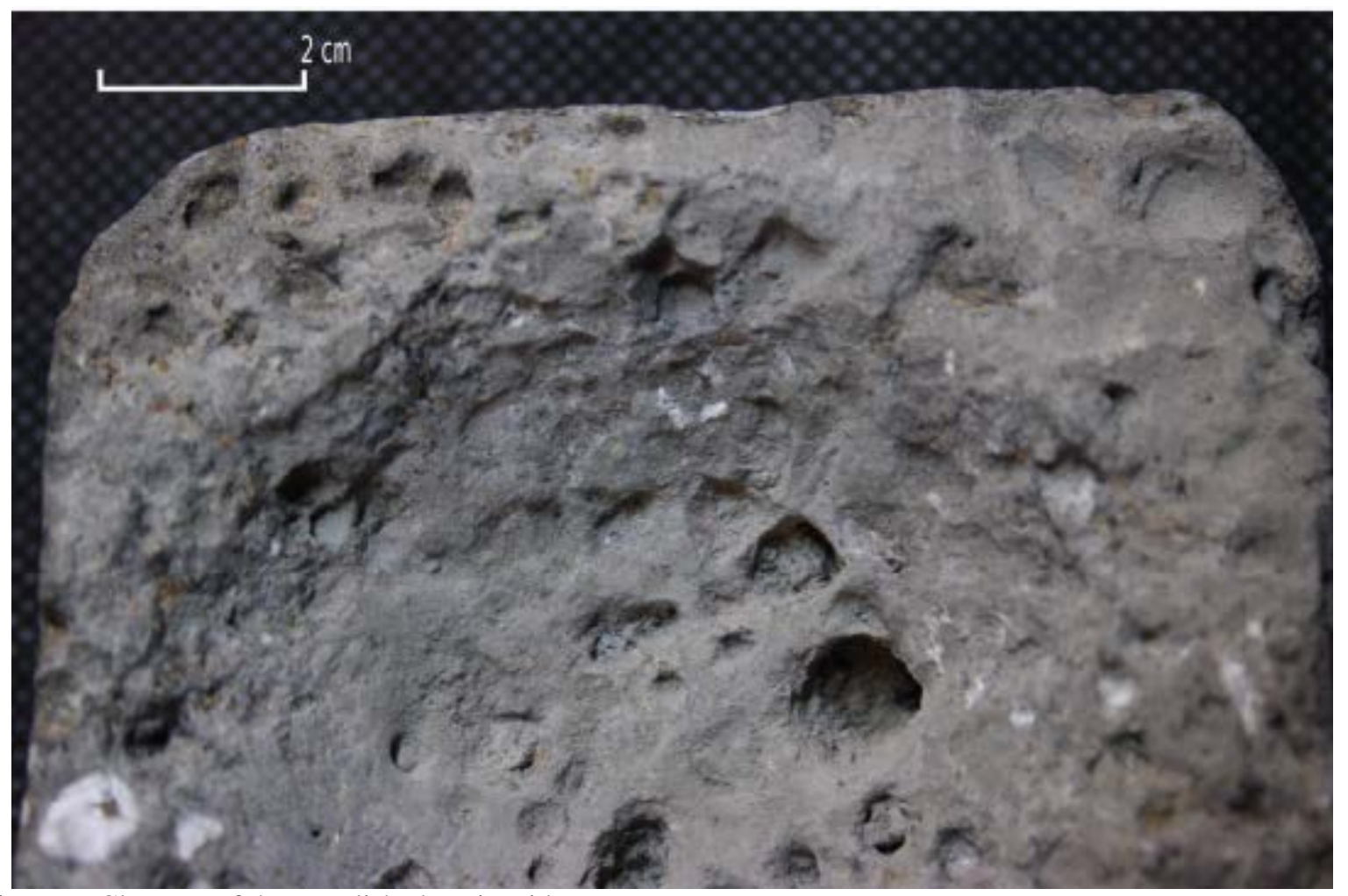

Figure 7. Close-up of the unpolished cavity side. 
It would be interesting to reproduce this experiment by using metal tools instead of stone tools in order to see if the former leave more visible marks on basalt, and what these may look like. In this respect, a close comparison between our experimental mortar and unfinished basalt vessels and ground stone tools known archaeologically, most notably the unfinished vessels from the Iron Age workshop at Hazor, in northern Israel (see Ebeling \& Rosenberg 2016; Gluhak et al. 2016) would prove highly useful since it would help to better interpret the tool marks visible on the archaeological material. Such a comparison may help us understand whether the tools marks known archaeologically are compatible with the tools and techniques we used in our experiment, or point to different tools and techniques.

After the cavity was opened, one side of it was polished by rubbing, adding water mixed with basalt powder. Though the cavity's rough surface is beneficial if the mortar is to be used to grind or pound other substances (e.g., food, see Wright 1992:72), a smooth and polished surface may be preferred for vessels used as containers or for special purposes (Figure 8).

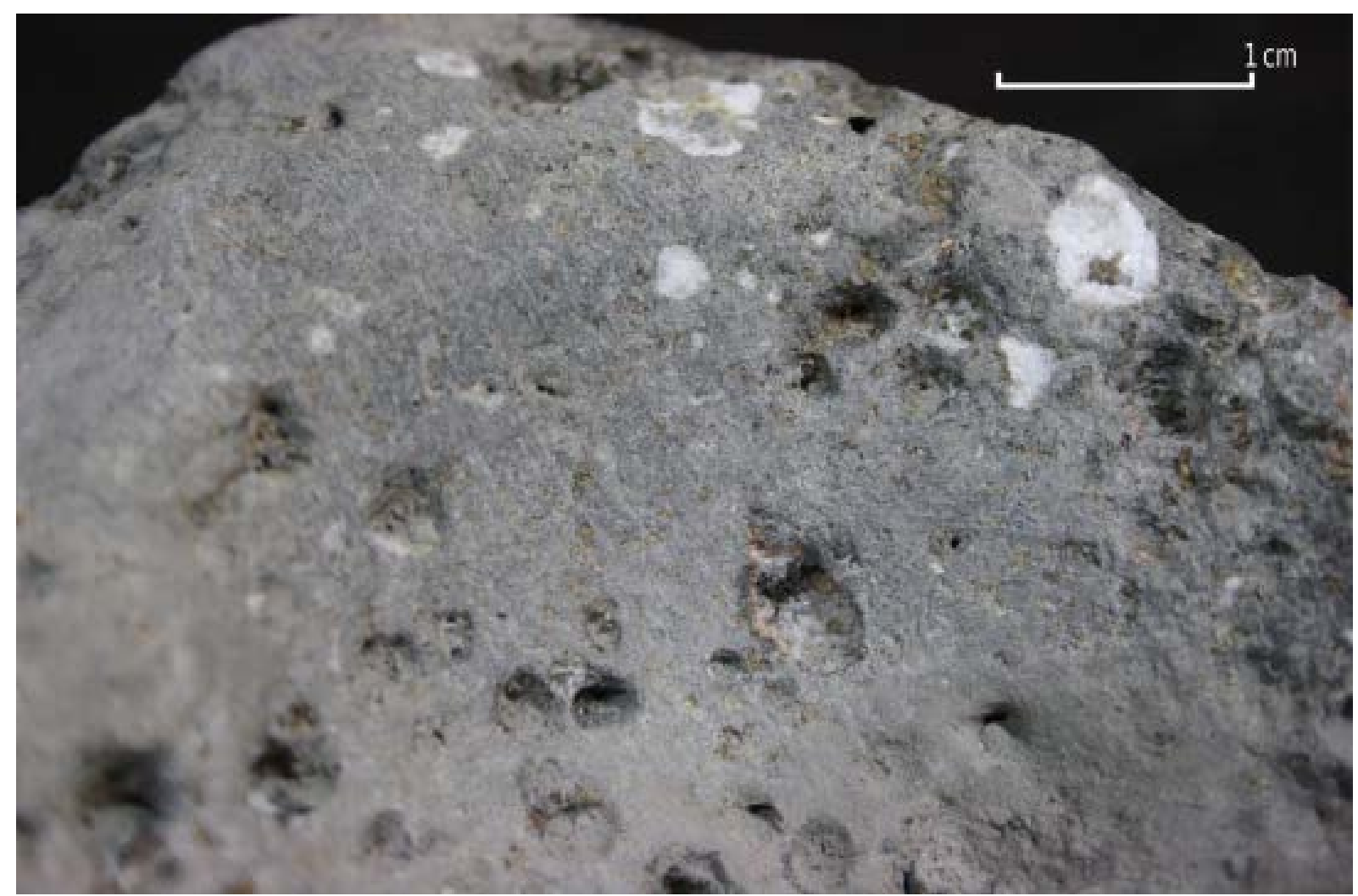

Figure 8. Close-up of the cavity side that was polished using the water and basalt powder mixture.

To sum up, the results of this experiment demonstrate that: 1) basalt tools are effective to work basalt; 2) basalt tools need not be made specifically for stoneworking, provided that they have a suitably sharp tip; 3) working tools were used for both coarse and fine pecking; 4) the level of damage endured by the working tools is very high, producing a great deal of powder and many chips; and 5) basalt tools similar to those used in the experiment will leave no clearly visible marks on the working surface. We would add that there was a similarity of the first working tools we used for this experiment to cylindrical pestles; the efficiency of this tool and the high level of damage it sustained may suggest that some of the numerous broken pestles found at Natufian sites in the southern Levant might have been involved in the manufacture of mortars, though more evidence would be needed to support this hypothesis.

Another interesting observation can be offered by comparing our results (summarised in Table 1) with those of previous similar experiments, shown in Table 2. It can be seen that the 
amount of material (measured in cubic centimetres, hereafter $\mathrm{cm}^{3}$ ) removed per hour in our experiment (17.1) is close to those removed per hour in other experiments where granite ground stone tools were made (17.5 and 16). Sandstone ground stone tools, on the contrary, lost much more material in the same time period. In terms of hardness, basalt, granite and sandstone are quite comparable (all the three rank in positions 6-7 in Mohs scale), but it is likely that the difference in texture between, on one side, basalt and granite (both igneous rocks), and, on the other side, sandstone (a sedimentary rock), plays a crucial role in causing the first two rocks wear down more slowly than sandstone. This information can be used to estimate how many hours it took in the past to make large ground stone tools and rock-cut utensils, thus enabling researchers to calculate roughly the investment of such a production in terms of labour requirements and intensity in past societies.

Table 2. Experimental studies replicating ground stone tools. Abbreviations: N/A - not available.

\begin{tabular}{|c|c|c|c|c|c|}
\hline References & Material & $\begin{array}{c}\text { Cavity } \\
\text { capacity } \\
\left(\mathrm{cm}^{3}\right)\end{array}$ & $\begin{array}{l}\text { Time } \\
\text { (h) }\end{array}$ & $\begin{array}{l}\text { Blows per } \\
\text { hour }\end{array}$ & $\begin{array}{c}\text { Volume removed } \\
\text { per hour }\left(\mathrm{cm}^{3}\right)\end{array}$ \\
\hline Buonasera 2015 & sandstone & 168 & 3.4 & N/A & 49.4 \\
\hline $\begin{array}{l}\text { Schneider \& } \\
\text { Osborne 1996: } 35\end{array}$ & granite & 140 & 8.0 & 8400 & 17.5 \\
\hline $\begin{array}{l}\text { Leventhal \& Seitz } \\
1989\end{array}$ & granite & 275 & 17.2 & 2674 & 16.0 \\
\hline Current paper & basalt & 30 & 1.75 & 7800 & 17.1 \\
\hline
\end{tabular}

By examining Table 2, another observation emerges concerning the great deal of effort that went into the hollowing out of the cavity during our experiment. Despite the fact that the $\mathrm{cm}^{3}$ of material removed per hour in our experiment is comparable with the other experiments, the number of blows per hour observed in our experiment is only slightly lower than that of Schneider and Osborne's experiment (Schneider \& Osborne 1996: 35), in which a larger cavity was hollowed out. There may be a number of factors behind this phenomenon (e.g., different raw materials and working tools used in the respective experiments), but it is certainly possible to conclude that the pecking technique is an extremely strenuous technique (see also Osborne's comments about pecking in Schneider \& Osborne 1996: 35). This leads us to think that a combination of techniques may have been preferred by ancient craftsmen. The two techniques mentioned in the introduction of this paper, percussion blows applied to an isolated section of the cobble and percussion flaking, are two possible techniques which, in combination with pecking, can allow the craftsman to reduce to form a cobble more efficiently, saving time and energy. In addition to this, the use of metal tools for basalt object manufacture needs also to be considered, and future experimental studies may be designed to measure the effectiveness of metal working tools on basalt and compare it to stone working tools'. It is worth noting that a combination of different techniques applied to ground stone tools manufacture was observed ethnographically (e.g., Hayden 1987: 25-30).

To conclude, our experiment added data on basalt mortar production. The results of the experiment can help understanding tool marks visible on unfinished basalt artefacts in the archaeological record, to evaluate time and energy spent to produce ground stone tools in the past, and hopefully will stimulate comparable experiments and research in this field. 


\section{References}

Adams, J. L. 2001, Ground Stone Analysis: A Technological Approach. University of Utah Press, Salt Lake City, 336 p.

Aschmann, H. 1949, A metate maker of Baja, California. American Anthropologist, New Series, 51 (4): 682-686. doi:10.1525/aa.1949.51.4.02a00350

Bryan, B. 1961, The manufacture of a stone mortar. The Masterkey, 4: 134-139.

Buonasera, T. Y. 2015, Modeling the costs and benefits of manufacturing expedient milling tools. Journal of Archaeological Science, 57: 335-344. doi:10.1016/j.jas.2015.03.018

Cerutti, R. A. 1986, Basalt stone-knapping experiments. In: The Archaeology of the Picacho Basin, Southeast California, (Pendleton, L., Ed.), Wirth Environmental Services, San Diego: p. 167-172.

Cook, S. 1973, Stone tools for Steel-Age Mexican? Aspects of production in Zapotec stoneworking industry. American Anthropologist, New Series, 75(5): 1485-1503. doi:10.1525/aa.1973.75.5.02a00180

Ebeling, J., \& Rosenberg, D. 2016, A basalt vessel workshop at Iron Age Hazor - Its context, products and implications. Journal of Field Archaeology, 40(6): 665-674. doi:10.1080/00934690.2015.1101941

Ebeling, J. R., \& Rowan, Y. M. 2004, The archaeology of the daily grind: ground stone tools and food production in the Southern Levant. Near Eastern Archaeology, 67(2): 108117. doi:10.2307/4132366

Eitam, D. 2009, Late Epipaleolithic rock-cut installations and ground stone tools in the Southern Levant: methodology and typology. Paléorient, 35(1): 77-104. doi:10.3406/paleo.2009.5279

Eitam D., Kislev, M., Karty, A., \& Bar-Yosef, O. 2015, Experimental barley flour production in 12,500-year-old rock-cut mortars in Southwestern Asia. PLoS ONE, 10(7). doi:10.1371/journal.pone.0133306

Forrest, C. 2008, The nature of scientific experimentation in Archaeology: experimental Archaeology from the Nineteenth to the mid Twentieth Century. In: Experiencing Archaeology by Experiment. Proceedings of the Experimental Archaeology Conference, Exeter 2007, (Cunningham, P., Heeb, J., Paardekooper, R., Eds.) Oxbow Books, Oxford: p. 61-68.

Gluhak, T., Rosenberg, D., \& Ebeling, J. 2016, Raw material variability as archaeological tools: Preliminary results from a geochemical study of the basalt vessel workshop at Iron Age Tel Hazor, Israel. Journal of Lithic Studies, 3(3): 169-189. doi:10.2218/jls.v3i3.1677

Hayden, B. 1987, Lithic Studies Among the Contemporary Highland Maya. University of Arizona Press, Tucson, 387 p.

Huckell, B. B. 1986, A Ground Stone Implement Quarry on the Lower Colorado River, Northwestern Arizona. Cultural Resource Series Monograph Vol. 3, State office of the Bureau of Land Management, Phoenix, $61 \mathrm{p}$.

URL: http://www.blm.gov/style/medialib/blm/wo/Planning_and_Renewable_Resources /coop_agencies/new_documents/az.Par.70562.File.tmp/Arizona_3.pdf 
Lemonnier, P. 1992, Elements for an Anthropology of Technology. University of Michigan, Ann Arbor, 129 p.

Levanthal, A., \& Seltz, G. 1989, Experimental archaeology mortar replication study: description and analysis. In: Results of the General Development Plan Archaeological Test Excavation Conducted at Ca-Mnt-185/H, Garrapata State Park, (Motz, L., Abbink, E., Hines, P., Hylkema, M.G., Kimbo, E., Leventhal, A.M., Schwaderer, R., Seitz, G., \& Swiden, C., Eds.), California Department of Parks and Recreation, Sacramento: p. 142-150.

Malina, J. 1983, Archaeology and experiment. Norwegian Archaeological Review, 16(2): 6978. doi: 10.1080/00293652.1983.9965385

Rosenberg, D., \& Garfinkel, Y. 2015, Sha'ar Hagolan 4. The Ground-Stone Industry: Stone Working at the Dawn of Pottery Production in the Southern Levant. Israel Exploration Society, Jerusalem, 336 p.

Roux, V. 2010, Lecture anthropologique des ensembles céramiques. Les Nouvelles de l’Archéologie, 119: 4-9. doi:10.4000/nda.957

Schneider, J. S. 1993, Aboriginal Milling-Implement Quarries in Eastern California and Western Arizona: a Behavioral Perspective. Unpublished Ph.D. dissertation, the University of California, Riverside, 309 p.

Schneider, J. S. 1996, Quarrying and production of milling implements at Antelope Hill, Arizona. Journal of Field Archaeology, 23 (3): 299-311. doi:10.2307/530484

Schneider, J. S., \& Osborne, R. H. 1996. A model for the production of portable stone mortars and bowls. Pacific Coast Archaeological Society Quarterly, 32(4): 27-40.

Speth, J. D. 1972, Mechanical basis of percussion flaking. American Antiquity, 37(1): 36-60. doi:10.2307/278884

Treganza, A. E., \& Valdivia, L. L. 1955, The manufacture of pecked and ground stone artifacts: a controlled study. Reports of the University of California Archaeological Survey, 32: 19-29.

Wright, K. 1992, A classification system for ground stone tools from the prehistoric Levant. Paléorient, 18 (2): 53-81. doi:10.3406/paleo.1992.4573 